\title{
Ärzte in Handschellen: Wie gefährlich ist das neue Antikorruptionsgesetz?
}

_ Der parlamentarische Beratungsprozess für ein Gesetz zur Bekämpfung der Korruption im Gesundheitswesen ist nahezu abgeschlossen. Die Rechtspolitiker der Koalitionsfraktionen haben sich in diesem Zusammenhang auf die Definition erlaubter und erwünschter medizinischer Kooperationen geeinigt. Derartige Kooperationen werden nicht mehr unter einen grundsätzlichen Generalverdacht gestellt, wie dies ursprünglich der Fall war. Gestrichen wurde ein Passus, nach dem die Strafbarkeit an die Verletzung von „berufsrechtlichen Pflichten zur Wahrung der heilberuflichen Unabhängigkeit“ geknüpft worden wäre.

Rechtsexperten zufolge hätte dies zu einer ungleichen Behandlung und zu Rechtsunsicherheit geführt. Das Berufsrecht ist nämlich in den einzelnen Bundesländern unterschiedlich geregelt. Somit hätte es vorkommen können, dass das gleiche Verhalten eines Arztes in einem Bundesland erlaubt, in einem anderen aber als Korruption strafbar gewesen wäre. Darüber hinaus ist in einigen Gesundheitsberufen gar kein Berufsrecht vorhanden, womit ebenfalls Defizite bei der Gleichbehandlung und Gerechtigkeit aufgetreten wären.

\section{MMW-KOMMENTAR}

Das ist eine schöne Nachricht, doch an einer anderen Stelle kommt es für die Ärzte dicke. Korruption im Gesundheitswesen soll nämlich nun doch als sogenanntes Offizialdelikt gesehen werden. Das bedeutet, dass entsprechende Ver-

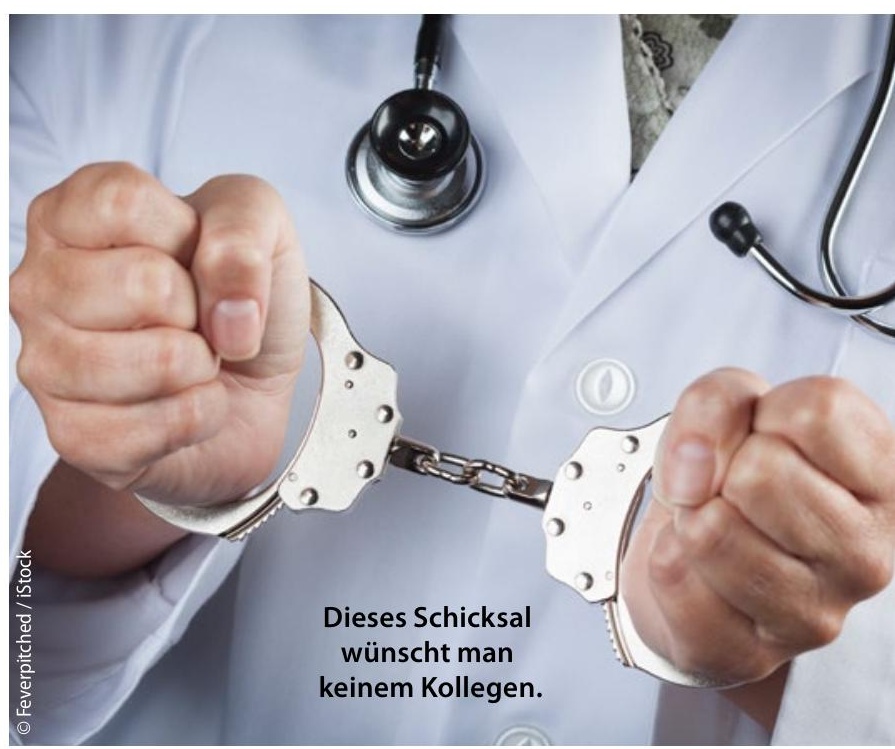
dachtsfälle von den Staatsanwaltschaften von Amts wegen verfolgt werden. Ein konkreter Strafantrag, wie er ursprünglich im Gesetzentwurf vorgesehen war, wird gar nicht mehr nötig sein. Der Gesetzentwurf ist im Juli 2015 vom Bundeskabinett verabschiedet worden.
Die zweite und dritte Lesung im Bundestag kann nach der jetzigen Einigung noch im April 2016 stattfinden, sodass das Gesetz noch vor der Sommerpause in Kraft treten könnte.

\section{Europäischer Arztausweis könnte kommen}

Krankenpfleger, Apotheker, Physiotherapeuten, Bergführer und Immobilienmakler haben ihn schon: den Europäischen Berufsausweis (EBA). Es handelt sich dabei um ein rein elektronisches Verfahren für die Anerkennung von Berufsqualifikationen zwischen den EU-Mitgliedsstaaten. Der EBA soll allerdings nicht das bisherige System der gegenseitigen Anerkennung von Berufsabschlüssen ersetzen, sondern vielmehr eine frei- willige Alternative darstellen, um in Bezug auf bestimmte Berufsgruppen das Verwaltungshandeln zu erleichtern.

\section{MMW-KOMMENTAR}

Erste Erfahrungsberichte von Angehörigen dieser Berufsgruppen sowie der für die Ausstellung zuständigen Behörden stellte die Europäische Kommission im Rahmen des Binnenmarktforums Ende März 2016 in Brüssel vor. Bisher wurden 570 EBA ausgestellt.
Wann der Berufsausweis auch für andere Berufsgruppen - z. B. Ärzte - zur Anwendung kommen soll, steht noch nicht fest. Die Europäische Kommission kündigte zunächst für das Jahr 2017 eine Konsultation zum bisherigen System des EBA an. Im Anschluss an diese soll evaluiert werden, für welche weiteren Professionen der EBA eingeführt werden sollte. Der durch die Kommission getroffenen Vorauswahl müssen dann noch die EU-Mitgliedsstaaten zustimmen. 